\title{
TRES TRISTES TIGRES EN LA JAULA VERBAL: LAS ANTINOMIAS DIALECTICAS Y LA TENTATIVA DE LO ABSOLUTO EN LA NOVELA DE GUILLERMO CABRERA INFANTE
}

\author{
Por \\ E. VOLEK \\ Arizona State University Tempe
}

“[...] la novedad de Un coup de dés consiste en ser un poema crítico. [...] la unión de estas dos palabras contradictorias quiere decir: aquel poema que contiene su propia negación y que hace de esa negación el punto de partida del canto, a igual distancia de afirmación y negación. La poesía, concebida por Mallarmé como la única posibilidad de identificación del lenguaje con lo absoluto, de ser absoluto, se niega a sí misma cada vez que se realiza en un poema [...] salvo si el poema es simultáneamente crítica de esa tentativa. La negación de la negación anula el absurdo y disuelve el azar. [...] la noción de poema crítico entraña la de una lectura y Mallarmé se refirió varias veces a una escritura ideal en la que las frases y palabras se reflejarían unas a otras y, en cierto modo, se contemplarían o leerían. [...] En su movimiento mismo [...] el poema engendra sus sucesivas interpretaciones. [...] No hay una interpretación final de Un coup de dés porque su palabra última no es una palabra final. [...] No es una imagen ni una esencia; es [...] un puñado de signos que se dibujan, se deshacen y vuelven a dibujarse. Así, este poema [...] no dice nada y es el lenguaje en su totalidad."

Octavio Paz, “Los signos en rotación,” El arco y la lira, 2a ed. (México: Fondo de Cultura Económica, 1967), pp. 171-274.

Tres tristes tigres (en adelante TTT) se parece fenoménicamente mucho a ese libro de la "Contradicción Considerada como una de las Bellas Artes"(p. 419) , del que discuten en "Bachata" dos "tristes tigres", Silvestre y Arsenio, durante su última "venida" al tablado literario. Las contradicciones, en efecto, llenan el espacio verbal de una solapa a otra y junto con la actitud lúdica a más no poder (mejor que falte la literatura que el juego, dicen los mismos en otro lugar de ese memorable "masturhablarse", [p. 416]) han producido uno de los

\footnotetext{
1 Las páginas entre paréntesis se refieren a la edición de la obra en Biblioteca Breve de Bolsillo, Barcelona: Seix Barral, 1970
} 
libros más libres de la literatura mundial, libro que ha hecho vacilar no sólo las convenciones del género novelístico y narrativo, sino también las bases del propio acto literario.

TTT representa indudablemente una escritura extrema, otro intento de alcanzar el límite absoluto de la creación literaria; este límite, sin embargo, es, en principio, inalcanzable, porque una jugada concreta jamás abolirá el azar. La alusión al famoso poema mallarmeano no es casual; éste representa otro ejemplo de la escritura nacida de la conceptualización del fracaso en alcanzar el absoluto literario. El comentario que le hace Octavio Paz, resumiendo el trabajo crítico de los últimos decenios, servirá, a su vez, de contrapunto y de escolio de nuestra empresa.

Al tratar de desenredar el "poker narrativo" (p. 425) de TTT, otra tarea imposible de hacer en términos absolutos, consideraremos algunas contradicciones fundamentales, contradicciones que se convierten en antinomias dialécticas que subyacen a la estructura de la obra. En la estructura, que entendemos en el sentido dinámico, funcional y semiótico que le dio la Escuela de Praga, ${ }^{2}$ estas antinomias están densamente trabadas y compenetradas, de manera que toda separación es artificial y está motivada por las necesidades del análisis y de su exposición didáctica.

Comencemos con la antinomia más obvia.

\section{El caos y el orden}

A primera vista, la obra parece ser puro caos y muy poco una novela. Tal fue su primera recepción por la crítica, y sólo paulatinamente, a partir de las justificaciones con que se excusaba el aparente caos, iba emergiendo la percepción de cierto orden, de cierta estructuración.

La causa de esta primera impresión que produce la obra está en la dislocación cubista de la identidad y de las entidades, o mejor, de la ilusión de la identidad, dislocación llevada a cabo consecuentemente sobre varios niveles estructurales. El manejo del personaje de Laura nos ilustrará bien este procedimiento. Siguiendo el orden en que el lector puede darse cuenta de ello, Laura está vista desde fuera por Arsenio (en "La casa de los espejos") y por Silvestre (en "Bachata"); es la mujer anónima psicoanalizada de las sesiones numeradas; es el primer narrad or del "Sueño de la amiga"(pp. 420-421); y es el narrador anónimo de la primera sección de "Las debutantes" (pp. 23-27). O sea, el reconocimiento va desde la mitad y desde el final hasta el comienzo. En otro ordien, la extensión va desde pura objetividad hasta la extrema subjetividad (el sueño). Cuesta mucho esfuerzo identificar todos estos fragmentos multiperspectivistas y reconocer tras ellos la unidad del personaje.

\footnotetext{
${ }^{2}$ Para la orientación y bibliografía elementales ver Emil Volek, "Semiotics of Art: Prague School Contributions", Clio, 8, No. 3 (1979), 439-443.
} 
Y todo esto se puede extender aún a otros planos de la estructura. Veáse, por ejemplo, el "mundo representado", dislocado en los múltiples puntos de vista por los personajes, por su constelación, enfoques y funciones en la trama narrativa. Y a propósito, ¿quiénes son los "tres tristes tigres" que anuncia el título? Pueden ser dos, cuatro o hasta seis (los cuatro obvios más Bustrófedon y Rine, uno autor de las parodias y de las "memorias" y el otro, de la "traducción"; y serían siete si contára mos al autor como personaje de la obra). La consolación está en que el título es un trabalenguas y no necesariamente una indicación del número de los personajes principales, y que connota también otros aspectos de la novela.

Igualmente está dislocado el plano de la historia como story. En lugar de historias completas y compactas se dan fragmentos, reducciones de varios tipos, además dispersos en el texto y entretejidos con otros fragmentos heterogéneos. A veces queda sólo el núcleo del conflicto, su "sombra" o mera posibilidad, que luego ni se realiza (por ejemplo, Silvestre y Arsenio, por Laura); a veces la fábula se reduce a una crónica ${ }^{3}$ ("se hizo célebre y se murió", podría ser el resumen de la "historia" de La Estrella). La narración en primera persona queda a veces anónima y desvinculada largo tiempo de su contexto (las narraciones de Arsenio y de Laura).

Otros ejemplos nos conducirían ya a otras antinomias. Así, de un solo hecho se origina una "literatura" múltiple (el cuento del bastón "perdido"y los reparos de Mrs. Campbell, las famosas parodias, etc.), recogida en varios "borradores" (las traducciones), etc.

De este modo, las entidades compactas están dislocadas y barajadas a manera del montaje cubista. ¿Hay algunas leyes de este montaje?

Examinemos la composición de la obra. Si al leer nos anotamos en una línea horizontal los nuevos temas o núcleos épicos, llegamos al capítulo "Rompecabeza"(pp. 207-224), situado casi exactamente en la mitad del libro, y de ahí parece como si los temas se repitiesen en orden inverso: las parodias, que corresponden al relato de Mr. Campbell; las secuencias de la mujer psicoanalizada y de "Ella cantaba boleros"; y la "Bachata", que comienza en forma paralela a "La casa de los espejos" y que es un extenso comentario sobre la solución de la primera parte.

En este sentido, el movimiento trazado por TTT correspondería al antiguo procedimiento griego llamado bustrófedon; al mismo tiempo, Bustrófedon,

${ }^{3}$ Término de B. Tomashevski; significa "ordenamiento puramente cronológico del material narrativo, sin ninguna trama". La teoría narrativa de los formalistas rusos está a nalizada en Emil Volek, "Die Begriffe Fabel und Sujet in der modernen Literaturwissenschaft", Poetica, 9, No. 2 (1977), 141-166; la versión espa ñola abreviada apareció en Roland Barthes et al., Lingüística y literatura, sel. e intro. de R. Prada Oropeza (Xalapa: Universidad Veracruzana, 1978), pp. 133-147. 
con mayúscula, es en cierto sentido el personaje central de la obra. Pero hay todavía más: el comentario sobre las "memorias" que dejó Bustrófedon (el "discurso cero" anunciado por "Algunas revelaciones") parece terminar en un discurso que se desintegra (p. 270); en realidad, hay que leer el final alternadamente de izquierda a derecha y de derecha a izquierda. TTT sería entonces en más de un aspecto una bustronovela.

Si ahora examinamos los materiales distribuidos sobre este eje de la composición, en esta forma bustrofedónica, vemos que tiene lugar todavía otro desdoblamiento: en la primera parte, la vida de los personajes, la atmósfera de la vida nocturna habanera se dan como auténticas. Esta ilusión realista de una mimesis directa se desvanece cuando esta realidad se desdobla y pasa por el filtro de la "literatura" (en el sentido de la "literatura en la literatura") hasta alcanzar su opuesto, hasta transformarse en puro juego del lenguaje, en que el lenguaje se repliega sobre sí mismo y se aleja de la referencialidad, aunque sin separarse de ella por completo. Como rebotando de este límite absoluto, el movimiento vuelve atrás, pasando por el filtro de las parodias y desembocando en la parte final, la cual es más bien una síntesis de los dos polos y no mero reflejo simétrico e inverso de la primera parte. Esta distribución divide la novela en tres suprasegmentos, que no son sóloformales sino que tienen varias implicaciones semánticas. Es que la estructura artística no es simplemente un juego de formas geométricas sino que va emergiendo en un proceso semiótico de crecimiento contextual.

La parte intermedia cumple una función que la asemeja al espejo. El espejo, y el juego de desdoblamientos que produce, es, a su vez, uno de los símbolos centrales de $T T T$ y un importante elemento del juego intertextual. ${ }^{4}$ Desde el punto de vista del crecimiento contextual, el "espejo" central no sólo corta por la mitad o desdobla una serie de relatos, sino que vierte sobre ellos una nueva luz, tanto retroactiva como progresiva. Siguiendo la dirección progresiva, la tercera parte está contagiada, filtrada e infiltrada, por el carácter lúdico de la intermedia. Se da a entender constantemente que en aquella no se enfrenta la "realidad" sino la "literatura". La creación literaria es allí el tema principal, el pretexto del inacabable "masturhablarse" de dos "tristes tigres", Silvestre y Arsenio; se subraya el plano metanarrativo, la autoconciencia del texto como tex to literario e incluso como un libro impreso. El desdoblamiento del plano narrativo y la distancia irónica que ello supone, dan al texto el carácter autocrítico que se exige de una empresa literaria límite. Las tres partes de la novela en cierto sentido se reflejan y se transforman mutuamente y, de esta manera, "leen" unas a otras y engendran sus sucesivas interpretaciones.

\footnotetext{
4 Este aspecto fue estudiado recientemente por William L. Siemens, "Mirrors and Metamorphosis: Lewis Carroll's Presence in Tres tristes tigres", Hispania, 62, No. 3 (1979), 297-303.
} 
Además de la composición bustrofedónica y del desdoblamiento como en el espejo, hay más elementos que organizan el aparente caos. Fijémonos, por ejemplo, en que las erupciones del juego del lenguaje dividen el tercer suprasegmento casi exactamente en otras tres partes (cap. XI, pp. 322-335; y el "poema" "Si te llamaras Babel...", pp. 376-378, ambas pertenecientes a Arsenio). La novela se articularía entonces también como cajas chinas. Recordemos aquí la composición de la misma en forma de Bustrófedon y tanto el personaje Bustrófedon como el discurso bustrofedónico en ella; el espejo y los espejos y espejillos; el concepto de creación literaria como traducción y tantos ejemplos de la traducción en el texto; etc.

En el pla no de la historia como story, la obra se articula básicamente como una crónica por más selectiva y entretejida que sea, crónica que va, formalmente, del "Prólogo" al "Epílogo"; biográficamente, de la infancia de los personajes a su edad madura, y al casamiento de algunos y a la muerte de otros; históricamente, desde los años cuarenta hasta el verano de 1958, con ciertos anacronismos posteriores.

Los planos biográfico e histórico, a su vez, están cargados de un valor simbólico y mítico (la sombra vs. la luz; Laura como aurora; el simbolismo apocalíptico), que ya se ha estudiado, ${ }^{5}$ aunque, y es típico de los estudios mitológicos, sin ver la carga paródica de muchos de estos elementos (es especial del apocalipsis).

Todos est os y otros que se podrían enumerar son los elementos que cierran la estructura de TTT. Sin embargo, sería un error tratar de ver sólo este aspecto cerrado; ${ }^{6}$ la novela es lo suficientemente contradictoria, e imprevisible, como para dejarse apresar en algún lecho de Procusto de simples simetrías u oposiciones. Los elementos que hemos mencionado no crean sino sólo cierta armazón "profunda" de la estructura. Hay muchas aperturas en el plano fenoménico, y hay también cierta deliberada apertura semántica, que hemos detectado más claramente en el nivel de la historia como story, al hablar de la fragmentariedad, las lagunas y la reducción de la fábula a la crónica; y hay también necesariamente una apertura indeliberada, al nivel de la historia como history, causada por nuestra lectura siempre necesariamente histórica de la novela.

Ya este somero análisis ha revelado que la antinomia "el caos vs. el orden" no es disyuntiva ni estática ni marginal sino que pertenece al núcleo mismo de

\footnotetext{
5 Ver en especial William L. Siemens, "Heilsgeschichte and the Structure of Tres tristes tigres", Kentucky Romance Quarterly, 22, No. 1 (1975), 77-99.

"Últimamente, Josefina Ludmer ha intentado meter la novela en la chaqueta de fuerza de una estructura tal como la definen los recientes modelos franceses. Ver su artículo "Tres tristes tigres: órdenes literarios y jerarquías sociales", Revista Iberoamericana, Nos, 108-109 (julio-diciembre de 1979), pp. 493-512.
} 
las fuerzas estructurantes, fuerzas que dinamizan, dialectizan y aumentan la complejidad de la estructura de la obra.

Repasemos brevemente varias otras antinomias.

\section{La oralidad y la textualidad}

Siguiendo las declaraciones del autor ${ }^{7}$ y algunas teorizaciones de algunos de los personajes (especialmente Bustrófedon, p. 257), se ha tendido a subrayar excesivamente el aspecto oral, "la galería de las voces". Sin embargo, todas las manifestaciones de la oralidad no son sino sólo un polo de toda una gama variadísma de gestos del lenguaje que contiene la novela. Lo oral no se da, por supuesto, en una cinta grabada sino mediante una inscripción; pero la escritura en $T T T$ sólo en parte traduce, y traiciona, lo oral; en parte, y desde el comienzo mismo, introduce juegos ortográficos y tipográficos independientes de lo oral. Sin embargo, tras la escritura hay todavía el aspecto tipográficopictórico (los dibujos y el "discurso cero" sternianos, "poemas concretos", caligramas, etc.) y tras éste, la conciencia de la textualidad literaria: los supuestos "hablantes"se refieren a páginas escritas (p. 149; p. 264) y hasta a las páginas impresas en el libro que el lector está leyendo (p. 423; p. 445).

El reflejo mutuo de todos estos tipos de lenguaje les quita la careta de naturalidad aún a aquellos que más parecerían serlo y los revela a todos en su carácter convencional, en su "gramática" y en su "retórica" artificiales.

Entre los ejes del discurso ${ }^{8}$ predomina el aspecto no autoritativo, que desemboca en una actitud antiautoritativa y lúdica. El límite a que se apunta es la destrucción del código lingüístico convencional (pp. 221-222). El ataque se centra en particular sobre el signo. La relación entre el significante y el significado se somete a un frenético juego de motivación y de desfiguración, al que no se le escapan ni los nombres propios. Por supuesto, este juego del lenguaje total, autónomo, tiene sus implicaciones para y correlaciones en todos los otros estratos de la estructura.

Veamos rápido algunas antinomias más.

\section{La visión directa de la realidad vs. la visión mediata}

A la visión mediata pertenece toda autoconciencia del narrador como narrador, toda conciencia del lector, la autoconciencia de los personajes como personajes de la novela por escribir (son, por así decirlo, "personajes" avant la lettre, p. 404, esp. p. 408), todo comentario metanarrativo (p. 37, passim), y

\footnotetext{
7 Ver en especial la entrevista con Emir Rodríguez Monegal, "Las fuentes de la narración", Mundo Nuevo, No. 25 (julio de 1968), pp. 21-58.

${ }^{8}$ Ver Emil Volek, "Colloquial Language in Narrative Structure: Towards a Nomothetic Typology of Styles and of Narrative Discourse", Dispositio, 5, No. 13 (1980), en prensa.
} 
también la compleja intertextualidad de la obra, "el diálogo" con los precursores en la misma línea de la escritura narrativa, como Cervantes, Sterne, Carroll; con otras obras de arte u otras artes (teatro, cine); y también un "diálogo" las más de las veces paródico con el simbolismo bíblico. Subrepticiamente, y luego en forma cada vez más abierta, la "realidad" se desdobla y el "original" hasta está sustituido por o confundido irremediablemente con la ficción.

La realidad se convierte en teatro, en cine, en literatura, en ficción, en ilusión verbal. Por ejemplo, un personaje femenino declara que ha inventado al otro por medio de la cosmética (p. 156). O, para el colmo, Arsenio está recorriendo con su coche "la palabra kilómetro" (p. 317).$^{9}$ ¿Dónde ha quedado entonces la realidad "auténtica" y "original"? Se dice del cabaré Tropicana que es una parodia cuyo original debe de estar en Hollywood (p. 277). Es decir, la realidad que al comienzo de la novela "soñamos" como directa y auténtica, se desvanece, se refracta en el espejeo lúdico y se autoparodia.

El punto neurálgico de este mundo desquiciado del convencionalismo naturalizado, sacado de los códigos anquilosados de cierta literatura "realista", es otra antinomia, la entre el olvido y el recuerdo.

\section{El olvido y el recuerdo}

Es que este mundo depende tanto de la realidad referencial como de la conciencia que, mal o bien, la refleja. Una está sujeta al cambio, la otra, al olvido. La lucha del recuerdo contra el olvido es uno de los temas apasionantes y fundamentales de TTT. Es que el autor se ha decidido a fijar este recuerdo artísticamente, llevando a cabo una traducción de un material semiótico complejo (la realidad reflejada en cierta conciencia) a otro material (el lenguaje) y a otro ambiente (la literatura y el arte). Según el epígrafe de la novela, se trata de "imaginar cómo se vería la luz de una vela cuando está apagada". Esto no es un oxímoron, como se lo ha interpretado a veces, sino la expresión del esfuerzo por evocar artísticamente el mundo y la atmósfera irremediablemente perdidos de la vida habanera nocturna, del relajo y del choteo criollos. Sin embargo, esto no es todo; lo insólito del proyecto intelectual de Cabrera Infante es que junto con la reconstrucción de ese

\footnotetext{
9 El procedimiento de transformar la realidad en ilusión verbal es corriente en el humor y en la cultura carnavalesca. Por ejemplo, en Love's Labour's Lost de Shakespeare (I, ii), cuando Don Adriano se queja del duro compromiso de "estudiar, ayunar, no dormir y no ver damas" por tres años, su paje le da un buen consejo de cómo abreviar el término: ". . . how easy it is to put "years' to the word 'three,' and study three years in two words...".
} 
mundo perdido se plantea en toda su complejidad el mismo problema de la reconstrucción, o sea, de la creación artística. De ahí otra antinomia obsesionante, que se hace explícita en la tercera parte de la novela.

\section{La traducción y la traición}

La crítica en general, y la "derrotista" en particular, ha confundido la última palabra del escolio de $T T T$, la "Bachata", que acusa la traducción de traición, con la palabra final. La obra se acusa de traición, pero sigue creándose; y existe como un artefacto estético. Sin embargo, hay más; parece que nadie se ha fijado en que hasta esa acusación de traición está como minada sutilmente porque ella misma se traiciona, a su vez, como una traición: jal dormir!, el narrador remite a la página ciento uno del libro impreso; pero la referencia corresponde, en realidad, a la página trescientos cuarenta y uno; y las dos $t$ en "Tradittori" es otro guiño de ojo al lector. Es en este múltiple juego donde la acusación adquiere su pleno significado de autoparodia. Al mismo tiempo, esta última contradicción de nuestra expectación establece un puente hacia la discusión de "los contradictorios", que "eran grandes jodedores, de bromas macabrosas, que siempre hacían lo contrario de lo que se esperaba de ellos"(p.

407). Éste es el "último episodio" (p. 408) que, como se promete, confirmará el carácter de los personajes y de la obra. ¿Se podría esperar tal vez otra cosa del libro del tipo como lo es TTT? De esta manera, la constante acusación de traición no es simplemente un signo de resignación sino que más bien dinamiza y dialectiza el proyecto artístico en sus múltiples niveles.

En realidad, todo lo que revela el concepto de traición, o sea, la falta de identidad entre el signo y el referente, se aplica a cualquier obra literaria, artística y hasta al lenguaje mismo. Lo interesante en el proyecto artístico del escritor cubano es que revela esta situación, que aprovecha constante y explícitamente esta antinomia, que la tematiza, que la convierte en la fuerza motriz dialéctica de su juego artístico frenético, desmesurado, agónico y autocrítico; y es esta dimensión la que lo eleva al status de novela crítica en el sentido mallarmeano. Gracias a este juego dialéctico, la creación, la totalidad del discurso, está "a igual distancia de afirmación y negación". Pese a sus bromas sobre el estructuralismo, la obra de Cabrera Infante también participa del modo semiótico y metacrítico de la literatura y de la crítica actuales. Por la crítica del lenguaje y por el cuestionamiento de la creación artística, TTT es doblemente una metanovela.

Para concluir: las contradicciones en TTTno son sólo fenoménicas, o sea, las opiniones divergentes, el signo de la heterogeneidad del mundo, etc., ni son tampoco simplemente arbitrarias, acumuladas por el gusto de la contradicción misma, sino que son las antinomias dialécticas profundas, las fuerzas motrices del juego agónico total. El espejeo de las partes, de los niveles y de las 
polaridades les quita la careta de "naturalidad" aún a aquellos que más parecerían serlo. La mimesis no se escapa al juego, en TTT es un juego dentro del juego. En términos de la jerarquización de la estructura, ni la historia como story ni como history están en primer plano; a lo largo de la composición bustrofedónica de la novela, el énfasis se desplaza de la atmósfera de la ciudad, etc., al puro juego del lenguaje y, finalmente, al metanivel que sintetiza esta antinomia.

Dijimos al comienzo que TTT es uno de los libros más libres de la literatura mundial y que su libertad (o libertades) hicieron vacilar las convenciones del género narrativo y del propio acto literario. Como resultado, sin embargo, ha surgido no sólo una novela crítica, una metanovela en la terminología actual, sino también "la novela más típica de la literatura mundial", o sea, típica del carácter sumamente proteico de ese género literario. El aforismo de Viktor Shklovski a propósito de Tristram Shandy de Laurence Sterne ${ }^{10}$ es plenamente aplicable a su "eco" en Tres tristes tigres [tristr: tres tris ti-r-s]. Por supuesto, y es otro aspecto que se le escapa obstinadamente a la crítica, TTT no es simplemente un eco especularmente simétrico, sino que resulta transformado, enriquecido por el crecimiento contextual de la historia humana y del arte, y enriquecido también por el otro lado del espejo de la tradición que es la modernidad. Sólo implícita y cifradamente hemos podido aludir a este apasionante aspecto de la obra.

La novela es un puñado de signos que se dibujan, se deshacen y vuelven a dibujarse. Es todo un mundo y al mismo tiempo no dice nada: es el lenguaje en su totalidad, o mejor dicho, en sus metamorfosis proteicas llevadas al límite.

Por supuesto, una jugada de dados jamás abolirá el azar; pero esto no significa que, para los prisioneros de la historicidad, este juego fuera intrascendente.

10 O teorii prozy (Moscú: Federatsia, 1929), p. 161. 
